\title{
THE EFFECT OF FOREIGN SURFACES ON BLOOD COAGULATION ${ }^{1,2}$
}

\author{
By EUGENE L. LOZNER AND F. H. L. TAYLOR \\ WITH THE TECHNICAL ASSISTANCE OF HARRIET MACDONALD \\ (From the Thorndike Memorial Laboratory, Second and Fourth Medical Services (Harvard), \\ Boston City Hospital, and the Department of Medicine, Harvard Medical School, Boston)
}

(Received for publication November 1, 1941)

In the United States, the two-stage theory of blood coagulation is widely accepted. This theory recently reviewed by Quick (1) and Eagle (2) suggests that in the first stage prothrombin, calcium ion and thromboplastin interact to form thrombin. Thrombin, in the second stage, converts fibrinogen to fibrin. Plasma thromboplastin has been considered to be of platelet origin. The phenomenon of the initiation of coagulation when blood is shed has been considered by many investigators to be due to the disintegration of platelets with the release of thromboplastin.

It has been known for many years that the coagulation time of blood taken in paraffin tubes is much longer than that of blood taken in glass tubes. The explanation usually offered for this phenomenon is that the glass, acting as a foreign surface, destroys the platelets at a more rapid rate than occurs in the presence of paraffin. The increased amount of thromboplastin so liberated is then considered to be responsible for the shorter coagulation time in glass vessels. Nolf (3) has criticized this explanation. He states that his experimental data indicate that cell- and platelet-free plasma already contains all of the factors necessary for blood coagulation. He believes that the initiation of coagulation is the result of the direct modification of one or more of the constituents of cellfree plasma by contact with a foreign surface such as glass.

In view of this difference of opinion, it seemed advisable to reinvestigate the rôle which foreign surfaces play in the blood coagulation reaction.

\footnotetext{
1 Presented in part before the American Society for Clinical Investigation, Atlantic City, New Jersey, May 5 , 1941.

2 The expenses of this investigation were defrayed in part by a gift to Harvard University from the Smith, Kline and French Laboratories of Philadelphia, and in part by a grant given "In Recognition of Dr. Francis W. Peabody's Services to the Foundation" by the Ella Sachs Plotz Foundation.
}

The present communication reports certain observations on the effects of four such foreign surfaces. The materials investigated were glass, paraffin, collodion, and a synthetic plastic "Lusteroid." 3

\section{METHODS}

Coagulation times were determined on venous blood by Pohle and Taylor's (5) modification of the method of Lee and White (4). Platelet counts were made by a direct counting method (6). By this method "platelet" counts below 15,000 per $\mathrm{cu}$. $\mathrm{mm}$. are without significance since cell-free Berkefeld filtered plasmas will give such values due to the presence of non-specific refractile bodies. Venepunctures were made with an oiled syringe and needle, and only when the vein was entered on the initial attempt and with minimum trauma was the blood used for these investigations. Plasma globulin substance was made from cell-free plasma, as previously described (7), with such modifications as are given below. For the sake of brevity one typical experiment on each phase of the investigation is given. In all instances however, the results were repeatedly duplicated.

\section{EXPERIMENTAL}

The effect of foreign surfaces on the coagulation of platelet-free plasma

Experiments of this type in the past have been criticized on the basis that either specialized plasmas, such as bird plasma, were employed or that a non-physiological anticoagulant was added which might modify the system under investigation. Therefore, the initial experiments were performed on normal human blood plasma to which no anticoagulant was added. Normal human venous blood was taken with an oiled syringe and transfered to a Lusteroid tube. In one typical experiment the platelet count on the blood was initially 300,000 per cu. mm. The tube and contents were centrifuged in an angle head centrifuge at 4,200 r.p.m. for 10 minutes and the resultant crystal clear plasma removed by a collodion coated pipette to a

3 Obtainable in the form of centrifuge tubes from the International Equipment Company, Boston, Mass. 
second scrupulously clean and dry Lusteroid tube. The "platelet count" on this plasma was 8,000 per cu. mm., or within the blank for the method. Two $\mathrm{ml}$. of the plasma were transferred with collodioned pipettes to tubes of each of the four materials under investigation.

TABLE I

The effect of foreign surfaces on the coagulation time of platelet-free plasma prepared without any anticoagulant

\begin{tabular}{cc}
\hline \hline 2 ml. plasma placed in & Coagulation time \\
\hline Glass & minutes \\
Collodion & 11 \\
Paraffin & 64 \\
"Lusteroid" & 44 \\
\hline
\end{tabular}

The data shown in Table I indicate that coagulation occurred in the glass tube in 11 minutes, which is within the normal time for this subject. In tubes of the other three materials the coagulation time was markedly delayed. Since the plasma used was platelet-free, the effect of the glass surface could not reasonably be attributed to the lysis of platelets.

In order to allow for more extensive manipulation of plasma in determining the site of action of foreign surfaces, the remainder of the investigation was carried out on plasma from blood containing sodium citrate in a final concentration of 0.25 per cent as an anticoagulant. The concept that the presence of such an anticoagulant modifies the behavior of plasma toward foreign surfaces must be abandoned since the results of the following experiments, in which citrated plasma was used, are entirely comparable to the results already described in which no anticoagulant was used.

The site of action of the foreign surface

Normal human venous blood was obtained in the manner suggested and transferred to Lusteroid tubes containing the requisite volume of 2.5 per cent sodium citrate. Platelet-rich plasma was obtained by slowly centrifuging the blood at about 1500 r.p.m. for 10 minutes. Samples of the slightly opalescent plasma were placed in tubes of the four materials and kept at room temperature for one hour. Platelet counts were made and 2 ml. samples were transferred to Lusteroid tubes and the plasmas recalcified. The results of a typical experiment are shown in Table II. The data show that no significant change in the platelet counts occurred following the exposure of the platelet-rich plasma to the four foreign surfaces for one hour. Preliminary experiments have shown that platelet destruction can be followed readily by the direct counting method. It would appear, therefore, that in the presence of these four foreign surfaces there was no increased lysis of platelets. However, in spite of this observation, the coagulation time of the plasma which had been exposed to glass for one hour prior to its recalcification was markedly less than that obtaining for the three samples of plasma which had been exposed for the same length of time to the other three surfaces.

TABLE II

The effect of foreign surfaces on the platelet count and the coagulation time of recalcified * citrated platelet-rich normal human plasma

\begin{tabular}{lcc}
\hline \hline $\begin{array}{c}\text { Plasma incubated } \\
\text { one hour in }\end{array}$ & Platelet count & $\begin{array}{c}\text { Coagulation time in } \\
\text { "Lusteroid" }\end{array}$ \\
\hline & per mm. & minutes \\
Glass & 412,000 & 6 \\
Collodion & 414,000 & 18 \\
Paraffin & 412,000 & 20 \\
"Lusteroid" & 432,000 & 20 \\
\hline
\end{tabular}

* 2 ml. plasma $+0.4 \mathrm{ml} .0 .5$ per cent $\mathrm{CaCl}_{2}$.

To further rule out lysis of the intact platelet as the responsible agent in foreign surface effect, the observations were repeated, except that the normal citrated plasma was rendered free from platelets by centrifuging at 4,200 r.p.m. for 15 minutes before transferring to the tubes made of the four materials under investigation. The data of one typical observation (Table III) show that, when $2 \mathrm{ml}$. of such platelet-free plasmas are recalcified in Lusteroid tubes, the one exposed to glass for one hour coagulates in 11 minutes, which is

TABLE III

The effect of foreign surfaces on the plalelet count and the coagulation time of recalcified citrated platelet-free normal human plasma

\begin{tabular}{lcc}
\hline $\begin{array}{c}\text { Plasma incubated } \\
\text { one hour in }\end{array}$ & Platelet count & $\begin{array}{c}\text { Coagulation time in } \\
\text { "Lusteroid" }\end{array}$ \\
\hline & per $\mathrm{mm}^{\mathrm{3}}$ & minutes \\
Glass & 12,000 & 11 \\
Collodion & 8,000 & 30 \\
Paraffin & 4,000 & 39 \\
"Lusteroid" & 10,000 & 38
\end{tabular}


within the range usually encountered for the coagulation time of normal citrated plasma after recalcification in glass tubes. Those samples of plasma exposed to the other three surfaces for the same length of time had markedly prolonged coagulation times.

It has recently been reported that there exists in cell-free citrated normal human plasma a factor, independent of prothrombin and fibrinogen $(8,9)$, capable of reducing the coagulation time of hemophilic blood in vivo and in vitro. The effect of foreign surfaces on this plasma factor was studied. Normal citrated platelet-rich plasma was prepared without exposure to glass and transferred to tubes of glass, collodion, paraffin and Lusteroid. The plasmas were permitted to remain in contact with these surfaces for one hour at room temperature. One-tenth of a milliliter of each of these samples of plasma was introduced into Lusteroid tubes and $2 \mathrm{ml}$. of hemophilic blood, obtained without exposure to glass, were added as soon as possible after the venepuncture. The results of a typical experiment are shown in Table IV. It will be

TABLE IV

The effect of foreign surfaces on the platelet count and the clot-promoting activity for hemophilic blood of citrated platelet-rich normal human plasma

\begin{tabular}{ccc}
\hline \hline $\begin{array}{c}\text { Plasma incubated } \\
\text { one hour in }\end{array}$ & Platelet count & $\begin{array}{c}\text { Coagulation time in } \\
\text { "Lusteroid" of } 2 \text { ml. } \\
\text { hemophilic blood } \\
+0.1 \text { ml. plasma }\end{array}$ \\
\hline Glass & per $\mathrm{mm}^{3}$ & minutes \\
Collodion & 412,000 & 14 \\
Paraffin & 414,000 & 41 \\
"Lusteroid" & 412,000 & 40 \\
Control: No plasma added & 432,000 & 43 \\
\hline
\end{tabular}

observed that the normal plasma exposed to glass for one hour had a much greater clot-promoting power for hemophilic blood than had samples of the same plasma which had been exposed to the other three surfaces for the same length of time. The control coagulation time shown in Table IV is that obtained in Lusteroid tubes. The data also indicate that no lysis of platelets occurred during the one-hour exposure to the foreign surfaces.

The observations recorded above were repeated, using platelet-free plasma. For this purpose the normal citrated human plasma was centrifuged at 4,200 r.p.m. for 15 minutes. At the end of this procedure the "platelet counts" were within the blank for the method and the plasma was crystal clear. Portions of this plasma were again exposed to contact with the four foreign surfaces for one hour at room temperature. One tenth millimeter portions of these plasmas were tested, as described, against $2 \mathrm{ml}$. of hemophilic blood in Lusteroid tubes. The results obtained in one typical experiment (Table V) show that, although the citrated

TABLE $v$

The effect of foreign surfaces on the platelet count and the clot-promoting activity for hemophilic blood of citrated platelet-free normal human plasma

\begin{tabular}{ccc}
\hline \hline $\begin{array}{c}\text { Plasma incubated } \\
\text { one hour in }\end{array}$ & Platelet count & $\begin{array}{c}\text { Coagulation time in } \\
\text { "Lusteroid" of } 2 \mathrm{ml} \\
\text { hemophilic blood } \\
+0.1 \text { ml. plasma }\end{array}$ \\
\hline & per $\mathrm{mm}^{3}$ & minutes \\
Glass & 12,000 & 25 \\
Collodion & 8,000 & 88 \\
Paraffin & 4,000 & 95 \\
"Lusteroid" & 10,000 & 90 \\
\hline Control: No plasma added & 300 \\
\hline
\end{tabular}

normal plasma was platelet-free, nevertheless that portion exposed to glass had a far greater clotpromoting activity for hemophilic blood than did those portions exposed to the other foreign surfaces.

It would appear from the data thus far presented that variation in the rate of lysis of the platelets could not be the essential explanation of the foreign surface effect and that the fraction of normal cell-free plasma which is involved in the foreign surface effect is the same fraction which, when added to hemophilic blood, both in vivo and in vitro, results in a sharp reduction in its coagulation time. This point was further investigated.

The clot-promoting activity for hemophilic blood is associated with the euglobulin fraction of cellfree plasma $(8,9)$. This fraction has been called in publications from this laboratory "globulin substance" and by Howell (10) "plasma thromboplastin." Observations were made concerning the effect of foreign surfaces on the clot-promoting activity of globulin substance prepared by acid precipitation of diluted, citrated, cell-free normal human plasma in vessels of glass, collodion and paraffin. Lusteroid vessels other than tubes are not at present available so that this material could not be included in the observations. 
The acid precipitated globulin substance from each of the three vessels was dissolved in 0.9 per cent sodium chloride solution, equal in volume to the plasma from which it was derived. One tenth $\mathrm{ml}$. of these saline solutions was pipetted into the bottom of Lusteroid tubes and $2 \mathrm{ml}$. of hemophilic blood preserved from glass contact were added. The results (Table VI) show that

TABLE VI

The effect of forcign surfaces on the clot-promoting activity for hemophilic blood of "globulin substance" prepared from citrated normal human plasma

\begin{tabular}{|c|c|}
\hline $\begin{array}{c}\text { "Globulin subatance" } \\
\text { prepared in }\end{array}$ & $\begin{array}{l}\text { Coagulation time in "Lusteroid" } \\
\text { of } 2 \text { ml. hemophilic blood +0.1 ml. } \\
\text { "globulin substance" }\end{array}$ \\
\hline & minutes \\
\hline $\begin{array}{l}\text { Glass } \\
\text { Collodion } \\
\text { Paraffin } \\
\text { Control }\end{array}$ & $\begin{array}{r}10 \\
50 \\
62 \\
360\end{array}$ \\
\hline
\end{tabular}

the globulin substance from plasma exposed to glass throughout the procedure had significantly more clot-promoting activity for hemophilic blood than that prepared from plasma exposed to surfaces of the other materials.

\section{DISCUSSION}

The foregoing observations show that the effect of foreign surfaces on blood coagulation are essentially independent of the intact platelet. These studies indicate that the site of action of such surfaces is dependent upon a factor which is present in normal cell-free plasma, independent of prothrombin and fibrinogen (9), associated with the euglobulin fraction of the proteins (8) and concerned with the clot-promoting activity of plasma for hemophilic blood. That this globulin substance might be derived from damaged platelets cannot be excluded by the present observations. However, it is present in cell-free plasma, and foreign surfaces have entirely similar effects on platelet-free and platelet-rich plasma. The data presented clearly indicate that the effect of foreign surfaces is not accompanied by any increased lysis of the platelets prior to clot formation, as heretofore assumed.

Exposure to a glass surface had more effect in "activating" the factor involved than did surfaces of paraffin, collodion or Lusteroid. The term "activating" is applied to the effect of glass rather than explaining the effect of collodion, paraffin and Lusteroid as due to an "inhibition" of the plasma factor involved, because plasma placed first in glass vessels and then transferred to tubes of the other foreign surfaces behaves as plasma exposed to glass alone.

The exact mechanism of the foreign surface effect can at present be only hypothecated. A possible hint of the type of reaction involved lies in the work of Gortner and Briggs (11) who showed by streaming potential methods that the charge on a glass surface in contact with water is considerably greater than that on a paraffin surface. These authors have also suggested that a positively charged substance in blood may be adsorbed by a negative surface such as that presented by a glass interface. These demonstrations make it inviting to suggest that the foreign surface effect is due to the physico-chemical modification of one or more of the constituents of cell-free plasma.

The data of the present communication give experimental confirmation to some of the concepts of the initiation of coagulation expressed by Nolf (3). They also invite the speculation that the so-called "physiological anticoagulant" sought by many investigators as an explanation for the fluidity of circulating blood may be found in the probability that the vascular endothelium may resemble such surfaces as collodion, paraffin, and "Lusteroid" in its behavior toward some noncellular plasma constituent.

\section{SUMMARY}

1. The effects of four foreign surfaces-glass, paraffin, collodion and Lusteroid-on the initiation of blood coagulation were studied.

2. Glass was shown to have the greatest effect on initiating coagulation.

3. No lysis of the platelets was found following exposure of platelet-rich plasma for one hour to any of the foreign surfaces studied.

4. The data suggest that the foreign surface acts by some modification of some constituent of cell-free plasma, probably by physico-chemical change.

5. It is suggested that at least one of the plasma factors modified is the plasma euglobulin fraction known as "globulin substance" and called by Howell "plasma thromboplastin." 


\section{BIBLIOGRAPHY}

1. Quick, A. J., A classification of hemorrhagic diseases due to defects in the coagulation mechanism of the blood. Am. J. M. Sc., 1940, 199, 118.

2. Eagle, $H$., The present status of the blood coagulation problem. A symposium on the blood and blood forming organs. The University of Wisconsin Press, Madison, Wisconsin, 1939, 242.

3. Nolf, P., Eine neue Theorie der Blutgerinnug. Ergebn. d. inn. Med. u. Kinderh., 1912, 59, 275.

4. Lee, R. I., and White, P. D., Clinical study of the coagulation of blood. Am. J. M. Sc., 1913, 145, 495.

5. Pohle, F. J., and Taylor, F. H. L., The coagulation defect in hemophilia. The effect in hemophilia of intramuscular administration of a globulin substance derived from normal human plasma. J. Clin. Invest., 1937, 16, 741.

6. Pohle, F. J., The blood platelet count in relation to the menstrual cycle in normal women. Am. J. M. Sc., 1939, 197, 40.
7. Patek, A. J., and Taylor, F. H. L., Hemophilia. II. Some properties of a substance obtained from normal human plasma effective in accelerating the coagulation of hemophilic blood. J. Clin. Invest., 1937, 16, 113.

8. Lozner, E. L., and Taylor, F. H. L., The coagulation defect in hemophilia: Studies on the clot promoting activity associated with plasma euglobulin in hemophilia. J. Clin. Invest., 1939, 18, 821.

9. Lozner, E. L., Kark, R., and Taylor, F. H. L., The coagulation defect in hemophilia: The clot promoting activity in hemophilia of Berkefelded normal human plasma free from fibrinogen and prothrombin. J. Clin. Invest., 1939, 18, 603.

10. Howell, W. H., Hemophilia, the Wesley M. Carpenter Lecture. Bull. N. Y. Acad. Med., 1939, 15, 3.

11. Gortner, R. A., and Briggs, D. R., Glass surfaces vs. paraffin surfaces in blood clotting phenomenahypothesis. Proc. Soc. Exper. Biol. and Med., $1928,25,820$. 